\title{
La neuroética y la naturalización de la filosofía moral ${ }^{1}$
}

Ricardo Braun

Universidad de Lima

Recibido: 12 de junio de 2014 / Aceptado: 30 de agosto de 2014

En este artículo se discute la posibilidad de la naturalización de la filosofía moral a través de la incorporación de los recientes trabajos en neuroética. Aunque de manera preliminar, se puede argumentar que la neuroética puede servir como un anclaje empírico para la justificación de los criterios que toda teoría moral madura debiera pretender. Se defiende la tesis de que toda naturalización debe partir de un concepto naturalista amplio y no estrecho, como se define en la dicotomía ciencias naturales/ciencias humanas. Finalmente, se discuten algunas características de la neuroética, en el sentido de neurociencia de la ética - no ética de la neurociencia-, con relación a la posibilidad de naturalización, advirtiendo las limitaciones actuales y quizás futuras de la extrapolación inadecuada de los hallazgos neurológicos y la interpretación de técnicas como la neuroimagen funcional.

neurociencia / neuroethics / filosofía moral / naturalización / ciencia

\section{Neuroethics and the naturalization of moral philosophy}

In this article I discuss the possibility of the naturalization of moral philosophy incorporating recent discussions in neuroethics. As a working hypothesis, one could argue that neuroethics may serve as an empirical basis for the moral justification of criteria that any mature moral theory may have. I defend the thesis that any form of naturalization in contemporary science should embrace a form of a broad naturalization in contrast to a strict naturalization which characterizes the classic dichotomy natural/human sciences. Finally, I discuss some characterization of neuroethics, in the sense of neuroscience of ethics-as different to ethics of neuroscience - and its relationship to the possibility of the naturalization of morality, and discuss some reasons to be cautious about the neurological findings and their interpretation particularly with functional neuroimaging techniques.

neuroscience / neuroethics / moral philosophy / naturalization / science

\footnotetext{
1 Este artículo es un trabajo preliminar que forma parte de una investigación auspiciada por el Instituto de Investigación Científica de la Universidad de Lima, al cual agradezco por el apoyo recibido.

Correo electrónico: rbraun@ulima.edu.pe
} 
La naturalización de la filosofía moral tiene amigos y enemigos. Por un lado, la tradición filosófica informada con la ciencia empírica ha buscado un anclaje de la justificación moral en alguna realidad no definida moralmente, como, por ejemplo, los utilitaristas británicos que encontraban en el concepto de placer y felicidad $-\mathrm{y}$ sus contrapartes dolor e infelicidad - una fuente para el establecimiento de criterios para la evaluación moral. Los enemigos de la naturalización ven como un peligro el ingreso de ciencias como la neurología en la filosofía moral, puesto que sospechan que las explicaciones biologicistas privan la dimensión moral, emocional o humana, como dicen que ocurrió análogamente con las explicaciones bioquímicas del origen y mantenimiento de la vida.

Las preocupaciones sobre la biologización de los conceptos éticos no tienen por qué empobrecer la discusión en el campo ético. Todo lo contrario. Conforme aparece más información empírica de lo que somos y somos capaces de hacer, tendremos que reformular nuestras suposiciones tanto metafísicas como metodológicas. Y lo más importante, la ética no debería ser el monopolio de los filósofos o miembros de las religiones institucionalizadas. Es una preocupación humana en la que todos estamos inmersos, y por ello, lejos de promover una excesiva división y exclusión de la discusión ética, se debería promover la integración de diversas disciplinas en la tarea de elucidar esta problemática común. Puede parecer sorprendente, pero una conocida eliminativista mental, $\mathrm{Pa}$ tricia Smith Churchland, defiende esta postura en el contexto de la problemática de la ética con relación a la neurobiología:

Ningún grupo profesional o social está equipado para resolver estos problemas: ningún grupo o persona puede autoerigirse como la autoridad moral para responder. Tendremos que contar con las opiniones reflexivas y el sentido común sólido de las personas en todo lugar - en la industria, la academia, las instituciones militares, la prensa, la religión y los negocios- $-\mathrm{Ni}$ el dogmatismo ni la intolerancia ni la pretensión de superioridad moral pueden ayudar en el progreso. Básicamente, tenemos una razón para determinar cómo debemos proceder de la mejor manera (Churchland, 2005, p. 15).

El camino para la incorporación de las bases neurológicas de la conducta humana se denomina naturalización, y la discusión la organizo de la siguiente manera: la primera sección está dedicada a la discusión entre las posiciones naturalista y antinaturalista de la ética. En la segunda sección discuto la concepción naturalista definida por las ciencias naturales. Argumento que una posición así invita únicamente a un naturalismo estrecho y excluyente. En la tercera sección defiendo brevemente una 
posición naturalista más amplia, en la que las ciencias naturales y las ciencias humanas tienen un espacio común de investigación y discusión. En la cuarta sección presento dos concepciones del término neuroética, para señalar que el sentido de la neurociencia de la ética sería el adecuado para proporcionar un marco conceptual naturalizado de la filosofía moral. En la quinta sección justifico las razones por las que la neuroética proporciona los elementos adecuados para la naturalización de la moral. Finalmente, en la sección sexta presento algunas razones por las que tenemos que ser cautelosos en la interpretación y usos de los hallazgos neurológicos con relación a la conducta moral.

\section{Naturalismo y antinaturalismo Ético}

El naturalismo como concepto académico contemporáneo no es del todo claro, y eso sorprende, puesto que diferentes autores abogan por la naturalización de diversos métodos sin tener un concepto unívoco. El antecedente conocido ocurre en el periodo de la Ilustración, posición que suponía una visión antagónica a cualquier forma de "supernaturalismo", es decir, a la tesis de que existen seres superiores, espíritus inmateriales que intervienen causalmente en el mundo. Esa visión, que tenía además motivaciones políticas, dio paso a una concepción que ya no promovía tanto el antagonismo mencionado, sino que enfatizaba una cosmovisión en la que todo lo existen- te, incluido el ser humano, es parte de una realidad común, en la que solo las fuerzas naturales operan eficientemente. Varios filósofos, particularmente de la primera mitad del siglo $\mathrm{XX}$, autoproclamados "naturalistas", consideraban que los tradicionales problemas filosóficos —entre los más perennes, la ética - deberían estar enmarcados dentro una información e, incluso, una metodología científica, y de esa manera podría anclarse la justificación ética en la visión científica del mundo.

Pocos filósofos, en la actualidad, promoverían una visión supernaturalista que incluyera entes como almas inmateriales, espíritus, entelequias o tal vez dios, o eventos como milagros o magia. Sin embargo, son dispersos los esfuerzos por proporcionar una ética naturalizada que dé cuenta no solo de la genealogía del mismo fenómeno moral (¿por qué tenemos normas morales?), sino, más relevante, la justificación de, por lo menos, algunas normas morales.

\section{LA TESIS ANTINATURALISTA}

Para entender la diferencia entre una ética naturalizada y una que no lo es, el locus clásico lo encontramos en la obra de Kant. El esfuerzo de Kant por distanciarse de una justificación supernaturalista lo lleva a una alternativa no naturalista. Leemos en la Fundamentación de la metafísica de las costumbres: "¿No se cree que es de la más urgente necesidad el elaborar por fin una filosofía moral pura, que esté enteramente limpia de todo cuanto 
pueda ser empírico y perteneciente a la antropología?" (Kant, 1980, pp. 1-2). Y más adelante añade:

El peor servicio que puede hacerse a la moralidad es quererla deducir de ciertos ejemplos. Porque cualquier ejemplo que se me presente de ella tiene que ser a su vez previamente juzgado según principios de la moralidad, para saber si es digno de servir de ejemplo originario, esto es, de modelo; y el ejemplo no puede en manera alguna ser el que nos proporcione el concepto de la moralidad.

El distanciamiento del naturalismo se lee claramente en el ideal de la justificación moral:

"una metafísica de las costumbres, totalmente aislada y sin mezcla alguna de antropología, ni de teología, ni de física o hiperfísica" (1980).

Es entendible la motivación kantiana por evitar la justificación de las normas morales en razones psicológicas o antropológicas. Entre otras preocupaciones estaba la distinción entre la felicidad y lo bueno (" ¿Es todo lo que trae felicidad, necesariamente bueno?"). Sin embargo, su teoría produce contraejemplos que difícilmente sus defensores han podido contrarrestar. Una norma universal y absoluta como "no mentir", demostrada en la sofisticada prueba lógica de la universalización, la hace impracticable en innumerables situaciones. Cualquier persona que miente a la abuela sobre la pertinencia de un regalo de Navidad ("iQué linda chompa!") no parece encontrarse en una bancarrota moral. Y los casos de conflicto de deberes ("Debo salvar la vida o decir la verdad") producen una teoría que no proporciona un camino de solución. Por ello, surge la necesidad de contar con una fuente teórica, que proporcione una información empírica acerca de la naturaleza de las personas como agentes morales, y que eventualmente asista en la justificación de nuestra normatividad moral.

El problema que genera una propuesta como la kantiana es la fuerte división entre una filosofía moral (no naturalista) y una psicología moral (descriptiva únicamente). $\mathrm{Y}$ esta división tiene eco en filósofos muy distintos de Kant, pero que, sin embargo, promueven la no naturalización de la moral. Hume y Moore son los autores prominentes en argumentar en contra de la naturalización por otros motivos.

Básicamente, la argumentación de Hume se sostiene en la imposibilidad de derivar enunciados valorativos ("Es malo infligir dolor a una persona inocente por el solo hecho de provocarle sufrimiento") de enunciados fácticos (1978, pp. 458, 468). Un "debe ser" no puede ser deducido de un "es". Es decir, lo normativo no se puede inferir de lo descriptivo. Moore, en una versión distinta, arriba a la misma conclusión sosteniendo lo siguiente:

La ética busca descubrir qué son aquellas otras propiedades que 
pertenecen a todas las cosas que son buenas. Pero muchos filósofos han pensado que cuando nombran aquellas otras propiedades están en realidad definiendo lo bueno; mientras que estas propiedades, de hecho, no eran simplemente "otras", sino absolutamente y enteramente las mismas que lo bueno. Esto es lo que llamo la "falacia naturalista" [...]. Cuando dicen "El placer es lo bueno", no podemos creer que están afirmando meramente que "Placer es placer" y nada más que eso [...]. No tiene sentido decir que el placer es bueno, a menos que lo bueno sea algo diferente al placer (Moore, 1903, pp. 10, 12, 14).

La falacia naturalista ocurre, según Moore, cuando tratamos de hacer una equivalencia entre un predicado valorativo y un predicado fáctico. $\mathrm{Si}$ "bueno" significa "lo deseado", no podríamos preguntar: “¿Es bueno?” acerca de cualquier cosa que fuera deseada. Sería como preguntar: “¿Es lo que es deseado, deseado?'. Según Moore, para cualquier término que se quiera utilizar que tenga una carga naturalista (placer, dolor, satisfacción, realización, gratificación, etcétera), uno podría siempre preguntar: “¿Pero es bueno?”, “¿Es lo correcto?". Eventualmente, se caería en la pregunta sin respuesta que provoca el naturalismo.

Contra la suposición humeana de la derivación de valores de los hechos, constantemente vemos cómo el descu- brimiento de ciertos fenómenos en la naturaleza nos puede provocar la reflexión sobre lo que valoramos. Si yo creo que comer alimentos con bastante sal es bueno, dos informaciones pueden llevarme a cuestionar la ingesta de sal: saber que soy hipertenso y saber que hay una fuerte asociación entre la hipertensión y la ingesta excesiva de sal en la dieta. En efecto, las recomendaciones médicas (y estas son normas, prescripciones) se derivan claramente de hechos. La cantidad de recomendaciones que recibimos ("Debes ejercitarte por lo menos tres veces a la semana", "No debes exponerte al sol sin protección", "No debes tomar alcohol en exceso") es resultado de haber descubierto cómo nuestras conductas pueden afectar (positiva o negativamente) nuestra salud. Si vamos a la realidad psicológica, encontramos normatividad producto de determinados hallazgos y descripciones de la conducta humana. Tómese como ilustración las prácticas escolares que incluían el castigo físico como método pedagógico. El hallazgo de que no solo era inútil, sino también perjudicial, cambió nuestra normatividad en cuanto al trato que los escolares reciben de sus maestros. De hecho, nos parecería un acto de brutalidad que una profesora agreda físicamente a un estudiante, cosa que no tenía el mismo impacto décadas atrás.

La posición de Moore desencadena en una extraña existencia no natural de una suerte de "hechos morales", con 
propiedades distintas de las propiedades naturales. Pero esa consecuencia trae un problema mayor: ¿cómo es posible que las valoraciones morales tengan consecuencias en el mundo natural? $\mathrm{Si}$ creemos en la concepción de un cierre causal en la naturaleza, que todos los efectos físicos son resultado de causas naturales, y si los hechos morales están fuera de la naturaleza, entonces, ningún hecho moral tendría ocurrencia en el mundo físico.

Sería metafísicamente problemático suponer cómo hechos morales no naturales pueden tener fuerza motivadora alguna en los humanos. Como vimos anteriormente, una recomendación médica tiene efectos causales evidentes. En forma análoga, determinadas reglas morales tienen efecto sobre las personas; de lo contrario, no nos explicaríamos cómo es posible que tengan una capacidad para motivarnos. Es claro que la descripción no es lo mismo que la prescripción, pero de ahí que se concluya que las normas son no naturales sería tan no natural como afirmar que no hay nada real en promover la discriminación de las personas.

\section{El NATURALISMO DEFINIDO CON RELACIÓN} A LAS CIENCIAS NATURALES: NATURALISMO ESTRECHO

Hay una tensión entre la posibilidad de naturalizar la filosofía moral y una concepción influyente de la actividad científica. Esta tensión es resultado de suponer que todo concepto de naturalización se establece necesariamente desde el punto de vista de las llamadas ciencias naturales. Este concepto está inmerso en la doctrina denominada "naturalismo científico" (De Caro \& Macarthur, 2010).

El naturalismo científico puede resumirse en dos visiones: una metafísica y otra metodológica:

Visión metafísica del naturalismo científico: lo único que existe en el mundo son las entidades postuladas por la ciencia.

Visión metodológica del naturalismo científico: la investigación científica constituye, en principio, la única fuente genuina de conocimiento o comprensión.

Esta visión naturalista puede ser resumida en la siguiente cita del filósofo contemporáneo A. Danto:

El naturalismo es una especie de monismo filosófico de acuerdo al cual todo lo que existe u ocurre es natural en el sentido que de ser susceptible de la explicación a través de los métodos [...] paradigmáticamente ejemplificados por las ciencias naturales (1967, p. 448).

El problema con esta concepción de naturalismo es que inmediatamente sugiere un reduccionismo de la realidad a las entidades postuladas por las cien- 
cias naturales, y aquí, las ciencias naturales, usualmente, se refieren en último término a las ciencias físicas.

En la clásica dicotomía entre las ciencias se ha tratado de distanciar a dos clases de ciencias: las naturales y las humanas (algunos prefieren llamarlas sociales). Las tradiciones que han influido en desarrollar esta visión polarizada son conocidas: las ciencias naturales han estado enmarcadas dentro del modelo positivistadelacienciaempírica, buscando regularidades nómicas en el mundo; podemos rastrear el manto positivista desde la Ilustración hasta Galileo. Por otro lado, las ciencias humanas se nutren de las posturas de Weber, Dilthey y Kant, y de la tradición hermenéutica iniciada por Schleiermacher.

Parte de la explicación de la actual dicotomía entre las ciencias se debe a la prevalencia del modelo iniciado en el positivismo, al cual las ciencias humanas siempre fueron adversas. Y lo fueron, porque el positivismo y sus herederos tenían como fin metodológico el reduccionismo, que, sin duda, promueve la identidad de los objetos de estudio, tal como se señaló en el naturalismo metafísico.

Sin embargo, la división de las ciencias en forma dicotómica solo promueve una visión antinaturalista de los seres humanos. La brecha explicativa que se produce entre las ciencias naturales y las ciencias humanas conduce a la suposición explicativa de que somos seres sin un origen común con las demás cosas, o que tenemos capacidades que no pertenecen al mundo físico. Sin embargo, como se constata en muchas disciplinas, la discontinuidad de los seres humanos promueve más problemas de los que intenta evitar. Uno de esos problemas, precisamente, es la existencia de nuestra vida moral.

Asimismo, esta polarización conduce a algunos a relacionar el naturalismo científico solo en términos de la aceptación de una metafísica que toma como clases naturales exclusivamente a los objetos descritos por la ciencia física. Sin embargo, una visión del naturalismo científico no tiene por qué identificarse únicamente con las ciencias naturales, salvo que se considere una visión estrecha del naturalismo científico (Macarthur, 2010).

Un naturalismo estrecho se caracteriza por la visión del positivismo. Entre sus suposiciones podemos anotar el fisicalismo metafísicamente reduccionista, el fundamentalismo causalista y la unidad de la ciencia metodológicamente reduccionista.

El fisicalismo reduccionista sostiene que solo la física, y nada más que la física, proporciona el inventario de todo lo que hay en el mundo. Por ello, considera que, en realidad, todo lo que existe expresado en otro vocabulario, eventualmente, será reducido por las entidades postuladas por la física, ya sea presente o futura. El fracaso del reduccionismo 
ontológico muestra la debilidad de esta tesis, puesto que si bien se puede compatibilizar la pluralidad ontológica con un origen común, es precisamente esta pluralidad la que se manifiesta en las diferentes formas de organización que eluden la reducción ontológica, salvo la pérdida de las entidades en cuanto seres reales.

El fundamentalismo causalista es la tesis que sostiene que el mundo tiene solo una estructura causal y que las operaciones de los entes postulados por la física son las responsables de las causas eficientes. Los demás seres postulados por otras ciencias serían, en último término, epifenómenos y su actuación causal, por lo tanto, ineficaz.

Si se advierte, el fundamentalismo causalista supone que solo hay una historia causal posible. Pero esto no se concluye cuando es posible componer varias historias causales, si, entre otros factores, se toman los elementos pragmáticos como el contexto. En efecto, se pueden construir diferentes historias causales, lo que da lugar a un pluralismo causal. Esto último lo relacionamos con la visión de la unidad de la ciencia.

La unidad de la ciencia, promovida por el naturalismo estrecho, está vinculada al reduccionismo metodológico, que se inició desde mediados del siglo XX. En su clásico artículo de 1958, "The Unity of Science as a Working Hypothesis", Oppenheim y Putnam esbozaron el programa de la reducción de los términos y leyes de la ciencia a un nivel fundamental de explicación. El programa determina una sucesión de microrreducciones de un nivel de explicación a otro más básico. Los niveles jerárquicos van de más alto a más bajo: grupos sociales, seres humanos individuales, seres vivos multicelulares, células, moléculas, átomos, partículas elementales. Para Oppenheim y Putnam, microrreducir es explicar las propiedades del todo en términos de las propiedades de sus partes (1991, pp. 406-408). Después de todo, un objeto es simplemente la suma de sus partes. Por ejemplo, la química afirma que un pedazo de madera no es otra cosa que el arreglo de varios tipos de moléculas unidos; la física atómica nos dice que las moléculas están unidas por fuerzas; la teoría de partículas afirma que los átomos son conjuntos de partículas elementales, y así sucesivamente (Rohrlich, 1988, pp. 295-296). Oppenheim y Putnam tienen la visión de un estado ideal de la ciencia en que se complete la unidad del lenguaje y la unidad de la explicación (1991, p. 406). Ellos aceptaron que su propuesta era una hipótesis de trabajo, basada en argumentos metodológicos y en evidencia empírica. Sin embargo, como veremos, la propuesta presenta varios obstáculos.

De entrada, la microrreducción enfrenta un problema metodológico: el reduccionismo presupone las explicaciones de mayor nivel. Como vimos arriba, la meta de la microrreducción 
es el completo reemplazo de las explicaciones de mayor nivel por una de menor nivel. Esto significaría que las explicaciones de menor nivel continuarán a ese mismo nivel inferior. Pero los intentos reduccionistas muestran el uso continuo de términos e información de nivel superior.

Consideremos la teoría neurológica que utiliza la información sobre la "conciencia" y la "memoria". La información y los términos, típicamente, pertenecen a lo que usualmente nos referimos como estados psicológicos. Como puede inferirse, en la explicación reducida hay una implícita explicación de nivel superior. Una situación análoga sucede con las ciencias sociales, en las que el programa reduccionista requiere que los fenómenos sociales sean expresados con referencia exclusiva a individuos. Términos como maestro, preso, soldado, ciudadano, etc., podrían ser empleados en la reducción individualista. Aparentemente, se refieren a individuos, pero implícitamente se está apelando al nivel sociológico. Estos términos pueden tener significado solo cuando son entendidos en un contexto social, lo que significa una apelación al mayor nivel. Un "ciudadano" desprovisto de las instituciones sociales no es realmente un ciudadano, como un "maestro" sin escuela no es un maestro (Kincaid, 1986, p. 499). En las microrreducciones biológicas también encontramos que las explicaciones bioquímicas utilizan términos o funciones que presuponen hechos biológicos.

El caso de la biología nos lleva a analizar una siguiente dificultad para las microrreducciones: el problema de las realizaciones múltiples. Si la bioquímica, como un nivel reducido, necesita emplear la función biológica, es porque los acontecimientos explicados por la teoría de mayor nivel (biológica) pueden ser realizados (instanciados) por indeterminado número de tipos de entidades de nivel inferior (bioquímico). La reducción del sistema inmunológico a la bioquímica nos proporciona una buena ilustración. El término anticuerpo pertenece al vocabulario biológico. Cuando un cuerpo extraño, tal como una bacteria, ingresa al sistema biológico, el anticuerpo se une con el antígeno - la bacteria - para inducir su remoción. Los anticuerpos existen en los niveles biológicos - células, órganos, organismo-y tienen potencialmente millones de diferentes estructuras químicas. Una caracterización bioquímica del anticuerpo sería, ciertamente, falsa, porque no es la estructura bioquímica - una proteína- lo que hace de una proteína un "anticuerpo", sino que la proteína tiene una cierta secuencia de aminoácidos que le permite identificar a otra como un antígeno. Las secuencias tienen una estructura física única y pueden ser encontradas en muchas estructuras de tipos de anticuerpos (Kincaid, 1986, p. 585). 
La conclusión es clara. El tratar de reducir un término como anticuerpo no nos conduce a una explicación fructífera. Precisamente, lo que caracteriza a la entidad "anticuerpo" es su realizabilidad múltiple. El valor de la irreducibilidad de las explicaciones biológicas es que la biología reúne - a través de la descripción funcional- los fenómenos que se nos aparecen como diversos. Una única explicación bioquímica nos llenaría de detalles, pero no nos traería una unificación de los fenómenos. En una vena similar, Garfinkel, argumentando en contra de la reducción, sostiene que las microrreducciones, por su detallismo, en último término, no explican un fenómeno: "La micro-explicación incluye datos que son irrelevantes para el resultado y, por lo tanto, sepulta irreconociblemente a la explicación. Nos proporciona una vergüenza de riquezas $y$, en consecuencia, es menos útil" (1981, p. 56). El proceso adaptativo de la evolución produce diversas estructuras que comparten una función similar; diferentes mecanismos bioquímicos provocan similitudes funcionales. La biología toma esas similitudes para explicar los fenómenos que, de otro modo, tendrían poco en común: allí donde el enfoque bioquímico ve diversidad, la biología revela una importante unidad.

Los casos descritos pueden proporcionarnos un marco de referencia para la unidad que tengo en mente. La diversidad de la realidad, dada la evolución cósmica, requiere una apropiada construcción mental de la organización jerárquica de los fenómenos para aprehender las diferentes propiedades de los objetos (sean los átomos, la tierra, las células, los organismos, los grupos sociales, etc.). Inevitablemente, las diferencias de propiedades requieren un enfoque pluralista en la explicación, no solo de orden epistemológico, sino también ontológico. El proyecto reduccionista presupone una explicación ontológica monista. Pero esta presuposición no toma en cuenta la teoría científica, ni tampoco la práctica científica. Consideremos nuevamente la diferencia entre la física newtoniana y la relativista. Una habla de espacio curvo, la otra de fuerzas gravitatorias. Preguntar cuál metafísica es la correcta sería simplemente no entender el punto de la explicación física. Aquí hay dos ontologías. Cada una proporciona una intuición en la explicación de los fenómenos. Este ejemplo es análogo de muchos que encontramos en las diferentes ciencias. ¿Por qué deberíamos esperar que todo fuera explicado con una misma ontología? La historia reciente de la física nos demuestra la importancia de reconocer una metafísica pluralista. La controversia acerca de la mecánica cuántica nos proporciona una luz para darnos cuenta del mundo en el que vivimos. Y el mundo no parece estar de acuerdo con las expectativas de algunos reduccionistas. Como lo señala McMullin:

¿Por qué hemos pretendido que la ontología del micromundo sea igual 
al del macromundo? La tercera regla de Newton para filosofar (que decretaba que el macromundo debiera ser semejante al micromundo en todos sus detalles esenciales) no ha sido más que una esperanza piadosa (1984, p. 13).

Una metafísica pluralista no es incompatible con la unidad de la ciencia. Al contrario, puesto que no hay una última verdad científica conocida, la integración entre los niveles de las teorías puede demostrar ser una fuente de explicación más fructífera y acertada, que, de otro modo, nos presentaría un mundo de eventos inconexos.

\section{Naturalismo amplio}

$\mathrm{Si}$ se quiere superar las objeciones planteadas al naturalismo, el concepto de naturalismo debe proporcionar una visión integradora entre diferentes niveles de la explicación científica. Este naturalismo, en contraste con el naturalismo estrecho, es lo que se ha denominado naturalismo científico amplio (Macarthur, 2010).

De acuerdo con esta postura, las diferentes ciencias pueden ser naturalistas y comprometerse con las dos visiones arriba mencionadas, sin endosar la suposición de que el naturalismo es ejemplificado exclusivamente por las ciencias naturales. Esto significa que las ciencias humanas, así como otras ciencias, pueden tener un lugar en la concepción naturalista $\mathrm{y}$, al mismo tiempo, mantener sus propias suposiciones metafísicas y particulares métodos de investigación. Las ciencias humanas tendrán, también, un lugar en la empresa naturalista, puesto que no postulan entidades súper o no naturales, y proporcionan evidencia empírica de sus hallazgos. De hecho, la psicología, sociología, antropología y economía contemporáneas siguen desarrollando teorías y explicaciones que, como otras disciplinas científicas, gozan de la autonomía ontológica y metodológica que sus objetos de estudio demandan. La misma práctica científica institucional actual así lo constata (Fodor, 1994).

En un naturalismo amplio se reconocen las diferentes estructuras de la realidad $-\mathrm{y}$ en el caso que nos interesa, la acción moral humana-, las cuales, en una visión estrecha, hubieran quedado subsumidas en otros fenómenos (abordados por las ciencias físicas) que no parecen agotar su ontología y comprensión. La propuesta de incorporar una visión neurológica a la filosofía moral no hace sino enriquecer la comprensión de un fenómeno que tiene una pluralidad ontológica que requiere, en consecuencia, una pluralidad metodológica. De alguna manera, el pragmatista norteamericano John Dewey lo señaló en su obra Naturaleza humana y conducta: introducción a la psicología social: "La ciencia moral no es algo como una provincia separada. Es el conocimiento físico, biológico e 
histórico puesto en el contexto humano en donde iluminará y guiará las actividades de los seres humanos" (1922, pp. 204-205). E insistió en proporcionar una visión empírica de la naturaleza de la moral: "Puesto que la moral se ocupa de la conducta, se desarrolla a partir de hechos empíricos específicos. Casi todas las teorías morales, con la excepción del utilitarismo, han rechazado aceptar esta idea" (1922, p. 295). Veamos de qué manera la neuroética puede enriquecer la comprensión del fenómeno moral humano.

\section{Neuroética: dos Sentidos del CONCEPTO}

Inicialmente, la neuroética surgió como una rama de la bioética, con el fin de reflexionar sobre los problemas morales asociados a la manipulación cerebral. El término fue acuñado por William Safire, quien en 2002 organizó el primer simposio de neuroética, en el que participaron más de 150 personas, entre neurólogos, académicos de la bioética, políticos, abogados y periodistas. La misión del simposio, señalada por el organizador, fue abrir el camino para el nuevo territorio de una disciplina filosófica antigua, una disciplina parcialmente emparentada con la bioética, pero para la cual la ética de la ciencia del cerebro cobra mucho más sentido como investigación, de la manera en que ningún órgano puede hacerlo (Safire, 2002).
Este inicio definió la neuroética como el campo filosófico que discute lo correcto o incorrecto acerca del tratamiento o mejora del cerebro humano. En este primer sentido, la neuroética sería una subdisciplina de la bioética que estudia las implicancias éticas en la investigación y aplicación del cerebro. Este sentido resalta dos aspectos señalados por Roskies (2002): la ética en la práctica y las implicaciones éticas de la neurociencia. La ética, en la práctica, trata de elucidar los principios éticos que debieran guiar la práctica en la investigación neurológica y el tratamiento de las enfermedades neurológicas. Las implicaciones exploran los efectos que tienen los avances en la comprensión de nuestras funciones cerebrales en nuestras visiones filosóficas, sociales y morales.

El segundo sentido del concepto es el que Roskies $(2002,2006)$ denomina la neurociencia de la ética, que se entiende como la comprensión del comportamiento moral desde un enfoque científico empírico. Los estudios neurológicos que se emprenden están dedicados a la exploración de los sistemas cerebrales involucrados en las complejas conductas manifestadas en la vida moral. Este enfoque tiene como meta, al menos por ahora, el entendimiento de la neurobiología de la representación del razonamiento y valor moral de las consecuentes conductas.

La metaética tradicional ha tenido como uno de sus temas predilectos el 
análisis de la naturaleza de los valores morales, en particular, la naturaleza de las creencias y juicios propiamente éticos. Por ejemplo, ¿cómo diferenciamos entre creer que ayudar a una persona inválida es bueno, y creer que un tenista es bueno como jugador? ¿Existe una diferencia entre el juicio de una acción moralmente buena (ayudar a una persona inválida), y una evaluación que carece de una caracterización moral (jugar tenis)? Una de las formas de enfrentar esta pregunta desde la neurociencia de la ética es mediante técnicas de neuroimágenes, en las que se quiere clasificar las regiones cerebrales responsables de estas, supuestamente, distintas formas de creencias. Lo que se espera es poder tener evidencia empírica acerca de la particularidad (o no) del razonamiento moral, y si en verdad existe una similitud con otra clase de procesos mentales asociados a la evaluación moral.

Argumentando, también, por un segundo sentido del concepto de neuroética, Gazzaniga sostiene que este no debe limitarse a ser una bioética para el cerebro. Considera que la neuroética es el análisis de estos aspectos:

cómo queremos manejar los asuntos sociales de la enfermedad, la normalidad, la mortalidad, el estilo de vida y la filosofía de la vida, con la información de los mecanismos cerebrales subyacentes. No es una disciplina que busca recursos para la cura médica, sino una que fundamenta la responsabilidad personal en el contexto social más amplio. Es - o debiera ser- un esfuerzo para constituirse en una filosofía de vida basada en el cerebro (Gazzaniga, 2005a).

Como se podrá inferir, la incorporación de los hallazgos, la interpretación y la reflexión de la neuroética en la filosofía moral están relacionadas con el segundo sentido del término. El primer sentido continuará siendo un importante pero distinto referente en la aplicación de diferentes investigaciones y tratamientos que involucran nuestro sistema neuronal.

\section{¿̇POR QUÉ LA NEUROÉTICA ES UNA}

\section{CANDIDATA A LA NATURALIZACIÓN DE LA} FILOSOFÍA MORAL?

$\mathrm{Si}$, de acuerdo con la naturalización científica amplia discutida anteriormente, buscamos una ciencia que medie entre los fenómenos cerebrales y los fenómenos psicológicos y sociales, la neuroética parece encajar adecuadamente. En la actualidad, se está realizando una serie de estudios empíricos acerca de la percepción, la memoria, la toma de decisiones y otras funciones mentales en las que neurólogos y psicólogos trabajan integradamente. Estos estudios de grandes grupos neuronales empiezan a revelar, al menos, asociaciones entre las funciones mentales y un conjunto específico de poblaciones 
neuronales localizables. Estas asociaciones permiten formular explicaciones que pueden enlazar la neurología con la psicología en forma ascendente, o la neurología con la biología en forma descendente. De forma análoga, con la neuroética se halla un punto de encuentro entre la ciencia natural y la psicología. Recordemos que si se pretende una teoría que ubique a la mente humana dentro del mundo material, se requiere dar cuenta de la implementación cerebral de nuestras acciones, específicamente de nuestra vida moral.

No tomar en cuenta al cerebro al desarrollar una teoría ética sería desconocer al órgano mismo que produce nuestros fenómenos mentales. En este sentido, la neurociencia nos proporciona nuevas formas de entendernos a nosotros mismos en cuanto personas. De hecho, empiezan a replantearse conceptualmente términos asociados al lenguaje moral como son la personalidad, el autocontrol, la responsabilidad, la conciencia moral y otros que, eventualmente, cuestionan nuestras tradicionales creencias acerca del yo, la libertad, los otros y nuestros ideales morales y culturales.

Uno de los aspectos más relevantes en la naturalización de la moral, vía la incorporación de la neurociencia, es la comprensión.

Se puede ver el impacto de la neurociencia en la elucidación de algunos problemas de moral aplicada. Tómese los casos de personas en estado comatoso. Uno de los clásicos problemas que tienen relación con el dilema de la eutanasia es la determinación de la muerte de la persona qua persona. Las pruebas de neuroimagen funcional están conduciendo a algunos hallazgos sin precedentes y que permiten mejorar nuestro juicio acerca de esas personas. Como se trata de personas en estado de coma, estas técnicas nos proporcionan información acerca de la actividad mental, sin requerir una comunicación verbal o alguna similar. Sin extrapolar excesivamente los hallazgos, no deja de sorprender su posible interpretación a favor de los pacientes.

Los estudios de Schiff y colaboradores (2005) son uno de estos descubrimientos pioneros. Escanearon sujetos que se encontraban en lo que se denomina estado mínimamente consciente (EMC), definidos como pacientes que parecen vegetativos, pero que ocasionalmente responden a los estímulos del entorno. El escaneo se realizó mientras se les presentaba la grabación de un familiar que contaba una historia personalmente relevante, primero de manera normal y luego al revés. Los sujetos en EMC activaban una red de áreas relacionadas con el lenguaje como respuesta a la grabación con sentido, en comparación con la grabación al revés. Esto era consistente con la respuesta de personas normales del grupo control. En contraste, las personas vege- 
tativas, definidas como muertas en la zona cortical del cerebro, no mostraban procesamiento neural asociado con las funciones mentales.

Estos estudios y otros (Owen, Coleman, Boly, Davis, Laureys \& Pickard, 2006) han mostrado, al menos prematuramente, que se ha preservado el procesamiento neurocognitivo en el caso de los pacientes en estado de coma. Ciertamente, no quita la carga de las eventuales decisiones acerca del estatus como persona que conservan (o no), y si tiene sentido continuar manteniéndolas en un estado vivo, cuando su estado funcional cerebral no permite clasificarlas como personas propiamente. Pero estos hallazgos demuestran que nuestras futuras decisiones estarán, ciertamente, mejor informadas y, en consecuencia, se tendrá mejores fuentes para la evaluación de los criterios que se consideren relevantes en las decisiones morales.

Finalmente, un concepto que siempre ha sido tentador para justificar, por lo menos, algunas reglas morales como "Es moralmente incorrecto violar sexualmente a una persona" es la universalización. Es posible que la neuroética tenga algunas respuestas empíricas en la búsqueda de algún sustrato que nos equipare como especie. Por ejemplo, Gazzaniga (2005a) dedica la última parte de su libro a fundamentar biológicamente una ética universal. Subraya que el deseo de actuar de acuerdo con una creencia moral es el resultado di- recto de un proceso orgánico: la parte emocional del cerebro se activa cuando se consideran preguntas morales. Ya existe alguna evidencia - aunque no libre de fuerte controversia académicade la existencia de neuronas espejo que sugerirían que regulan nuestra conducta altruista y empática. Sin embargo, todavía es prematuro utilizar esos hallazgos preliminares para constituirlos en una teoría interdisciplinaria.

\section{LIMITACIONES ACTUALES DE LA} NEUROLOGÍA Y CAUTELA TEÓRICA

Algunos optimistas ven en la neurociencia una suerte de segunda Ilustración que hace eco de la nueva comprensión del universo que ocurrió en el siglo XVIII, la cual va a naturalizar el entendimiento de la humanidad y transformar la manera como pensamos acerca de nosotros mismos. Esto puede traer una nueva sociedad, más humana, en la que nos vemos como parte de un cosmos interconectado por fuerzas causales mutuas. Pero, para los menos optimistas, nos podría conducir a una conceptualización mecanicista simple, en la que se nos invite a desconocer la agencia moral y el valor moral de otros.

Cualquiera que ve un programa de divulgación científica sobre los escaneos cerebrales y las funciones mentales asociadas no deja de tener una impresión de asombro. Después de todo, lo sofisticado $-\mathrm{y}$ por momentos incomprensible - de la tecnología que com- 
portan estas técnicas contemporáneas crea un aura de omnipotencia a quienes interpretan los resultados de las neuroimágenes funcionales. Algunas personas pueden derivar, acríticamente, conclusiones acerca de la información que estas técnicas pueden ofrecer. De allí que, por el momento, una mirada crítica y una interpretación cautelosa sean normas valorativas acerca de la aplicación de la neurociencia en nuestro quehacer y decisiones morales. Veamos algunas razones.

En primer lugar, las neuroimágenes funcionales están siendo usadas para predecir algunas enfermedades o identificar estados mentales. Esto lleva a la posible suposición de una correlación necesaria entre estados cerebrales y estados mentales. Sin embargo, se debe recordar que, aun en los casos de anomalías cerebrales más dramáticos, es posible que no correspondan a conductas predecibles, emociones u otros estados mentales específicos. De alguna manera, se espera un determinismo causal al encontrar determinadas correlaciones. Pero el reduccionismo que puede engendrar esta asociación puede ser potencialmente peligroso. Después de todo, el cerebro no tiene por qué complacer nuestras suposiciones metafísicas, puesto que, tal como reza la ironía, podría ser que nuestro cerebro esté configurado de tal manera que nos determine a que veamos que "el cerebro es determinista", aun cuando no lo fuera.
La genética proporciona ilustraciones análogas que permiten aprender una lección. Recordemos que la biología humana es sumamente compleja. La era del genoma empieza con el denominado "dogma central", formulado por F. Crick, que indica que un gen - segmento de ADN - se traduce en un RNA mensajero, que a su vez produce una proteína. De este dogma se sigue que si se entiende la secuencia genética, podemos comprender las estructuras biológicas y los procesos a los que conduce. Después de varios años, la investigación genética ha señalado que este modelo es problemático, ya que genes similares producen efectos múltiples (pleiotropía) (Green, 2005). Mutaciones genéticas idénticas no siempre llevan a los mismos resultados fenotípicos. Parte de la explicación es la multicausalidad de los efectos en los que otros factores - entre genéticos, ontogenéticos y ambientales- pueden estar en juego. La determinación (o indeterminación) genética de la fibrosis quística es uno de esos ejemplos. Como señala Silverman, uno de los gestores del Proyecto Genoma Humano:

Puede ser que el gen no sea esencial en el fenotipo, o al menos comparte el escenario con otras influencias. Los factores ambientales, los tejidos y los factores citoplasmáticos claramente dominan los procesos de expresión fenotípica, que, a su vez, pueden estar afectados por una variedad de eventos interac- 
tivos de proteínas impredecibles (2004, p. 33).

La genética es diferente de la neurología, sin duda. Sin embargo, la lección que se aprende de la genética es que todavía puede haber una importante brecha entre nuestra habilidad para identificar estructuras y procesos cerebrales, y nuestra comprensión de sus relaciones con los pensamientos, las emociones, las conductas y la salud de los individuos.

En segundo lugar, está siempre presente el problema de la extrapolación de las observaciones empíricas. Gazzaniga proporciona un interesante argumento que se resume en la frase: "Mi cerebro me hizo hacerlo" (2005b, p. 145). Los hallazgos de la neurociencia cognitiva pueden sugerir interpretaciones y llevar a conclusiones injustificadas, particularmente, en el entorno de la aplicación de estos hallazgos en el derecho penal y otras áreas. Pero, como se sostiene, muchos defensores penales están interesados en los descubrimientos que atenúen la carga penal de sus clientes. En efecto, parecería que tanto más se sabe de neurología, menos responsabilidad tienen los procesados y los hallados culpables. Gazzaniga sostiene que la neurociencia, por ahora, no tiene tanto que decir acerca del tema de la responsabilidad personal o del libre albedrío, como la gente común imagina. Si la neurociencia identifica los mecanismos con los cuales el cerebro determina nuestra mente y nuestras acciones, ¿qué ocurre con el libre albedrío? El libre albedrío no tiene por qué morir. El hecho de que se sepa acerca de un mecanismo cerebral, o su disfunción, no significa que la persona que ejecuta la acción es automáticamente exculpada. La responsabilidad personal es algo que surge como interacción con otros seres humanos. Así, aun con el conocimiento del cerebro, no dejan de entrar en el paquete causal las reglas sociales de conducta, que también guían y determinan la acción personal.

Quiero concluir citando la visión integradora e interdisciplinaria que motiva el presente trabajo, en las palabras de Jean Pierre Changeux:

La búsqueda de bases neurobiológicas de la conciencia y de la racionalidad, lejos de empobrecer nuestra concepción de la identidad humana, ofrece una oportunidad sin precedentes para apreciar en su justa medida la variedad de la experiencia personal, la riqueza de la diversidad cultural y la diversidad de nuestras ideas sobre el mundo (2004, p. 6).

\section{BibliografíA}

Bhaskar, R. (1979). The Possibility of Naturalism: A Philosophical Critique of the Contemporary Human Sciences. Nueva Jersey: Humanities Press.

Changeux, J. P. (2004). The Physiology of Truth. Neuroscience and Human 
Knowledge. Cambridge, MA: Harvard University Press.

Churchland, P. S. (2005). Moral decision-making and the brain. En J. Illes (Ed.), Neuroethics: Defining the Issues in Theory, Practice and Policy (pp. 4-16). Nueva York: Oxford University Press.

Danto, A. (1967). Naturalism. En P. Edwards (Ed.), Encyclopedia of Philosophy (volumen 5). Nueva York: Macmillan.

De Caro, M., \& Macarthur, D. (Eds.) (2010). Naturalism and Normativity. Nueva York: Columbia University Press.

Dewey, J. (1922). Human Nature and Conduct: An Introduction to Social Psychology. Nueva York: Modern Library.

Fodor, J. (1994). Special Sciences (or: The Disunity of Science as a Working Hypothesis). En M. Martin \& L. McIntyre (Eds.), Readings in the Philosophy of Social Science (pp. 687700). Cambridge, MA: MIT Press.

Garfinkel, A. (1981). Forms of Explanation: Rethinking the Questions in Social Theory. New Haven, CT: Yale University Press.

Gazzaniga, M. S. (2005a). The Ethical Brain. Nueva York: Dana Press.

Gazzaniga, M. S. (2005b). Facts, Fictions and the Future of Neuroethics. En J. Illes (Ed.), Neuroethics: De- fining the Issues in Theory, Practice and Policy (pp. 141-148). Nueva York: Oxford University Press.

Green, R. M. (2005). From genome to brainome: charting the lessons learned. En J. Illes (Ed.), Neuroethics: Defining the Issues in Theory, Practice and Policy (pp. 105-122). Nueva York: Oxford University Press.

Hume, D. (1978). A Treatise of Human Nature. Oxford: Oxford University Press.

Kant, M. (1980). Fundamentación de la metafísica de las costumbres. (6. ${ }^{\mathrm{a}}$ edición, Trad.: M. García Morente). Madrid: Espasa Calpe.

Kincaid, H. (1986). Reduction, Explanation and Individualism. Philosophy of Science, 53, 492-513.

Macarthur, D. (2010). Taking the Human Sciences Seriously. En M. De Caro \& D. Macarthur (Eds.), Naturalism and Normativity (pp. 124-141). Nueva York: Columbia University Press.

McMullin, E. (1984). A Case for Scientific Realism. En J. Leplin (Ed.), Scientific Realism. Berkeley, CA: University of California Press.

Moore, G. E. (1993). Principia Ethica. Nueva York: Cambridge University Press.

Oppenheim, P., \& Putnam, H. (1991). Unity of Science as a Working Hypothesis. En R. Boyd, P. Gasper \& J. D. Trout (Eds.), The Philosophy 
of Science (pp. 403-427). Cambridge, MA: MIT Press.

Owen, A. M., Coleman M. R., Boly, M., Davis, M. H., Laureys, S., \& Pickard J. D. (2006). Detecting awareness in the vegetative state. Science, 313 (5792).

Rohrlich, F. (1988). Pluralistic Ontology and Theory Reduction in the Physical Sciences. British Journal for the Philosophy of Science, 39, 295-312.

Roskies, A. (2002). Neuroethics for the new millennium. Neuron, 35, 21-23.

Roskies, A. (2006). A case study in neuroethics: the nature of moral jud- gment. En J. Illes (Ed.), Neuroethics: Defining the Issues in Theory, Practice and Policy. Nueva York: Oxford University Press.

Safire, W. (2002). Introduction. En S. J. Marcus (Ed.), Neuroethics: Mapping the Field. Nueva York: Dana Foundation.

Schiff, N. D., Rodríguez-Moreno, D., Kamal, A., Kim, K. H., Giacino, J. T., Plum, F., \& Hirsch, J. (2005). MRI reveals large-scale network activation in minimally conscious patients. Neurology, 64, 514-523.

Silverman, P. (2004). Rethinking genetic determinism. Scientist, 18, 32-33. 
